\title{
Efficiency of self-healing cementitious materials with encapsulated polyurethane to reduce water ingress through cracks
}

\author{
B. Van Belleghem ${ }^{\mathrm{a}, \mathrm{b}}$, K. Van Tittelboom ${ }^{\mathrm{a}}$, N. De Belie ${ }^{\mathrm{a}} \bowtie$ \\ a. Magnel Laboratory for Concrete Research, Department of Structural Engineering, Faculty of Engineering and Architecture, \\ Ghent University, (Ghent, Belgium) \\ b. Strategic Initiative Materials (SIM), Tech Lane Ghent Science Park, (Ghent, Belgium) \\ $\triangle$ Nele.DeBelie@UGent.be
}

\begin{abstract}
Cracks in reinforced concrete elements can cause major durability issues due do the accelerated ingress of aggressive substances. In this study, repair of cracks was addressed by incorporating encapsulated polyurethane based healing agents in the cementitious material as an autonomous healing mechanism.

Capillary sorption tests showed that a high viscosity healing agent could reduce the water ingress in cracked mortar, but a large scatter in the results was found, resulting in a large range of healing efficiencies $(18-108 \%)$. The low viscosity polyurethane showed a more complete and consistent crack healing. Healing efficiencies ranging from 95 to $124 \%$ were observed (crack width up to $295 \mu \mathrm{m}$ ). The proposed healing mechanism is very effective in blocking the ingress of water. This will enhance the durability of cementitious materials and consequently extend their lifetime.
\end{abstract}

KEYWORDS: Mortar; Polymer; Durability; Ttransport properties

Citation/Citar como: Van Belleghem, B.; Van Tittelboom, K.; De Belie, N. (2018) Efficiency of self-healing cementitious materials with encapsulated polyurethane to reduce water ingress through cracks. Mater. Construcc. 68 [330], e159 https://doi.org/10.3989/mc.2018.05917

RESUMEN: Eficiencia de materiales cementíceos autocurados con poliuretano encapsulado para reducir el ingreso de agua a través de fisuras. Las fisuras en hormigón armado pueden causar graves problemas de durabilidad debido al ingreso acelerado de sustancias agresivas. En este estudio, la reparación de fisuras fue llevada a cabo mediante la incorporación de agentes de curado encapsulados, a base de poliuretano, en el material cementíceo como mecanismo de curado autónomo.

Los ensayos de absorción capilar mostraron que un agente de curado con alta viscosidad redujo el ingreso de agua en morteros fisurados, pero se encontró una gran dispersión en los resultados, lo que da lugar a un amplio rango de eficiencias de curado (18 - 108\%). El poliuretano de baja viscosidad mostró un curado de las fisuras más completo y consistente. Se observaron eficiencias de curado del 95 al 124\% (ancho de fisura de hasta 295 $\mu \mathrm{m})$. El mecanismo de curado propuesto es muy efectivo para bloquear el ingreso de agua. Esto mejorará la durabilidad de los materiales cementíceos y consecuentemente extenderá su vida útil.

PALABRAS CLAVE: Mortero; Polímero; Durabilidad; Propiedades de transporte.

ORCID ID: B. Van Belleghem (http://orcid.org/0000-0003-1294-1724); K. Van Tittelboom (http://orcid.org/00000002-7718-3189); N. De Belie (http://orcid.org/0000-0002-0851-6242)

Copyright: (C) 2018 CSIC. This is an open-access article distributed under the terms of the Creative Commons Attribution 4.0 International (CC BY 4.0) License. 


\section{INTRODUCTION}

Starting from the first reinforced concrete building in the mid-19th century, the use of reinforced concrete for buildings, bridges, roads, tunnels, dams and several types of other structures has been increasing throughout the years. In the early 20 th century concrete became one of the most widely used construction materials. By that time, the first codes for the design of reinforced concrete structures were published (1). By the mid-20th century a huge amount of reinforced concrete structures were built based on the available design codes. The strength and the structural behavior of reinforced concrete was well-known and documented by that time, but the long term durability of the structures was not yet well established. In the late 20th century a lot of concrete structures showed major deterioration due to durability problems. This caused a lot of repair and rehabilitation works on existing structures which had huge economic implications. In Europe, for example, it was estimated that $50 \%$ of the annual construction budget is spent on repair works (2).

The most common durability problem in reinforced concrete structures is without doubt the occurrence of corrosion of the reinforcing steel. Reinforcement corrosion has been widely reported in the literature over the last three to four decades. Within these reported cases, there are two main mechanisms for reinforcement corrosion: chloride induced or carbonation induced. The main mechanism causing these forms of corrosion is penetration of aggressive agents, such as chlorides or carbon dioxide into the concrete. However, in perfectly sound (uncracked) concrete, the penetration of these aggressive agents is fairly slow (depending on the concrete quality). By Van Belleghem et al. (3) it was shown for example that the expected service life of uncracked (fly-ash containing) concrete in a marine environment could reach up to 97 years. Yet a lot of reinforced concrete structures do not reach this lifetime without major repair works. The major cause for a lot of durability problems is the appearance of cracks during the lifetime of the structure. When cracks are present, aggressive substances can penetrate much faster in the concrete and cause rapid deterioration.

Aggressive agents are commonly transported through water. Hence, the measurement of water ingress in cementitious materials can give an idea about the durability. In most structures water mainly enters the cementitious material through capillary action (4), especially when cracks are present (5, 6). Consequently, the cumulative water absorption in function of time and the corresponding sorptivity coefficient are good parameters to qualitatively assess the durability of cementitious materials.

Reinforced concrete elements are in practice almost always cracked. The design of these elements allows a crack width that ranges from 300 to $400 \mu \mathrm{m}$ depending on the environmental class (7). As such, an interesting idea is to modify the concrete structure to give it the ability of restoring cracks by itself at the moment of their appearance. In this way, no manual repair works are needed anymore and further damage is avoided immediately. This idea of creating a so called self-healing cementitious material has drawn increasing attention during the last two decades (8-13). Several methods have already been adopted to equip cementitious materials with self-healing properties. One example is attempting to improve the autogenous healing capacity of the cementitious material through restriction of crack width making use of fibers (14-17) or by the addition of superabsorbent polymers $(18,19)$ or encapsulated water reservoirs $(20,21)$. However, in most of these studies it was concluded that only relatively small cracks $(<50-150 \mu \mathrm{m})$ could be healed through autogenous healing (22-24). In order to be able to heal cracks up to the aforementioned allowable crack width of 300 to $400 \mu \mathrm{m}$, it is necessary to modify the cementitious material in order to obtain autonomous crack healing. This modification of the concrete can be achieved in several ways. One way is through the incorporation of bacteria in concrete (25-31). Addition of bacterial spores can give the concrete an autonomous healing capacity by precipitation of calcium carbonate in the cracks. Another way of obtaining self-healing concrete is through embedment of encapsulated healing agents $(13,32-34)$. In this approach, a set of discrete brittle capsules filled with a healing agent are placed in the cementitious matrix. Crack appearance causes breakage of the brittle capsules and simultaneous release of the liquid healing agent in the crack. The healing agent then solidifies in the crack. Previous research showed that the permeability of cracked concrete could be reduced by a factor of 100 to 10000 due to autonomous crack healing (32). Water absorption tests on mortar specimens with artificially created cracks already showed that samples with autonomously healed cracks had a similar water absorption compared to uncracked samples (35).

In this study, the efficiency of the autonomous healing mechanism to reduce water ingress through cracks in cementitious materials is investigated through capillary water absorption tests on specimens with realistic cracks.

\section{MATERIALS}

\subsection{Mortar}

Ordinary Portland cement mortar was used for all specimens in this research. Sand with a grain size of $0-2 \mathrm{~mm}$, cement type CEM I 52.5 and water were mixed with a respective mass ratio of $6: 2: 1$ to obtain a mortar with a water-to-cement ratio of 0.5 . 


\subsection{Autonomous healing mechanism}

The healing mechanism in this research requires a set of brittle capsules filled with a healing agent to be distributed in the cementitious matrix. The capsules were cut to a length of $50 \mathrm{~mm}$ from long borosilicate glass tubes with an internal diameter of $3 \pm 0.05 \mathrm{~mm}$ and a wall thickness of $0.175 \pm$ $0.03 \mathrm{~mm}$. After cutting the capsules to the desired length, they were filled with a healing agent and the ends were sealed with a methyl methacrylate (MMA) based glue. Two different polyurethane (PU) precursors were used as healing agents in this study. The first PU precursor is a non-commercial product with a viscosity of $6700 \mathrm{mPas}$ at $25^{\circ} \mathrm{C}$. It was developed in the framework of another project (SHEcon) and has been used in previous research as healing agent for artificially created cracks $(35,36)$. The second PU precursor is a commercially available one with a viscosity of $200 \mathrm{mPas}$ at a temperature of $25^{\circ} \mathrm{C}$. Also this second precursor has already been used in previous research for self-healing of cementitious materials $(33,36,37)$. Further details about both polyurethane precursors can be found in (36). Since the viscosity of the first healing agent is more than 30 times higher than the second one, the first PU precursor is denoted as PU_HV (High Viscosity) and the second one is denoted as PU_SLV (Super Low Viscosity) in this paper.

\subsection{Mortar specimens with(out) autonomous healing mechanism}

Reinforced mortar prisms with dimensions of $40 \mathrm{~mm} \times 40 \mathrm{~mm} \times 160 \mathrm{~mm}$ were cast in wooden formworks. Two screw threaded reinforcement bars with a diameter of $3 \mathrm{~mm}$ were placed in the molds in order to be able to create a controlled crack in the mortar prisms. The bars were positioned at $10 \mathrm{~mm}$ from the bottom of the specimens and at $10 \mathrm{~mm}$ from the sides. The specimens with the autonomous healing mechanism contained two capsules filled with a PU precursor. The capsules were fixed in the center of the specimens by gluing them on thin wires between the reinforcement bars. Figure 1 shows the preparation of the molds for the specimens with self-healing properties. When the molds were prepared, they were half-filled with mortar. This first layer of mortar was then compacted on a vibration table for 30 seconds. Subsequently the molds were completely filled with mortar and vibrated again for another 30 seconds. After that, the specimens were put in an air-conditioned room with a temperature of $20 \pm 2{ }^{\circ} \mathrm{C}$ and a relative humidity of at least $95 \%$. 24 hours later, the mortar specimens were demolded and stored in the same environment for 27 days (curing period). (a)

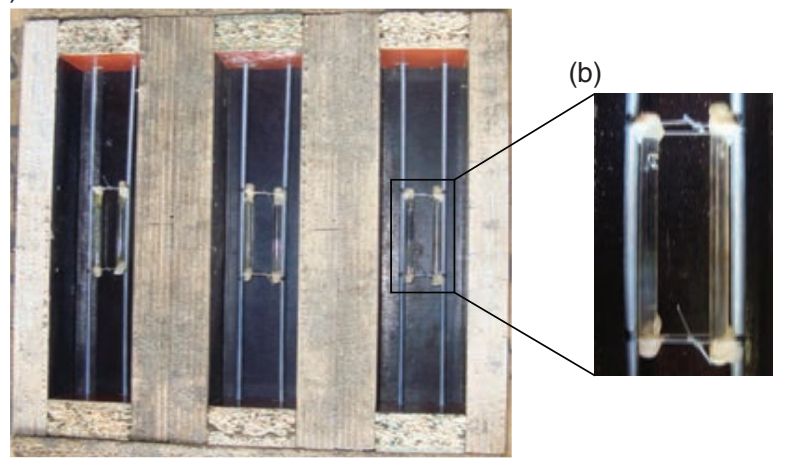

FIGURE 1. (a) Mold preparation for mortar prisms with self-healing properties; (b) Detail of the polyurethane filled capsules glued on nylon threads between the reinforcement bars

\section{METHODS}

\subsection{Crack creation and healing}

Cracks were introduced in the mortar prisms by means of a three-point bending test. Two different crack widths were targeted during the bending test to evaluate the healing efficiency for different crack widths. In order to register the width of the created crack during the bending test, a linear variable differential transformer (LVDT) was attached at the bottom of the sample using a small metal block and a thin metal plate. For some specimens a target crack width of $100 \mu \mathrm{m}$ was desired. Therefore, the specimens were loaded at a rate of $3 \mu \mathrm{m} / \mathrm{s}$ until a crack width of $400 \mu \mathrm{m}$ was obtained. Subsequently, the specimens were unloaded, causing the crack width to decrease to a value of around $100 \mu \mathrm{m}$ due to the presence of the reinforcement bars. For some other specimens a target crack width of $300 \mu \mathrm{m}$ was desired. These specimens were loaded at the same rate as previously mentioned, but until a crack width of $900 \mu \mathrm{m}$ was reached. During unloading the crack width then decreased to a value of maximum $300 \mu \mathrm{m}$.

For the specimens with the autonomous healing mechanism, the capsules broke due to the creation of the crack. Breakage of the capsules could be noticed during the bending test by popping sounds. Moreover, the capsule breakage was noticed by a sudden small drop in the force during loading of the specimens. After crack creation, all specimens were stored in a climate room at a temperature of $20 \pm$ $2^{\circ} \mathrm{C}$ and a relative humidity of $60 \%$ for 48 hours. During this period, the polyurethane that was released in the crack of specimens with the autonomous crack healing mechanism was given the time to harden inside the crack.

A total of 35 mortar specimens were prepared. An overview of the test series with their designation and the number of specimens per series is given in Table 1. 
TABLE 1. Designation of different test series

\begin{tabular}{llc}
\hline Designation & \multicolumn{1}{c}{ Description of test series } & Number of specimens \\
\hline UNCR & Sound mortar specimens without a crack & 3 \\
CR & Specimens without a healing mechanism where a crack was created & 15 \\
PU_HV & Specimens containing capsules filled with the high viscosity polyurethane & 9 \\
PU_SLV & Specimens containing capsules filled with the low viscosity polyurethane & 8 \\
\hline
\end{tabular}

\subsection{Crack width measurements}

Due to the fact that the crack width reduced during unloading and the fact that the LVDT was still a few millimeters away from the bottom of the specimen, the final crack width could not be accurately detected from the last reading of the LVDT during the bending test. Therefore, the width of all cracks was measured microscopically using a stereomicroscope. Seven microscopic images were taken along the length of the crack with an intermediate distance of $5 \mathrm{~mm}$. The crack width was measured three times on each image using the program ImageJ. Finally, the average width was calculated to represent the crack width of the crack in each sample.

\subsection{Water uptake through capillary absorption}

A capillary water absorption test was performed in a climate room at $20 \pm 2{ }^{\circ} \mathrm{C}$ and $60 \%$ relative humidity based on the European standard NBN EN 13057 (38). Before the start of the test, the specimens were preconditioned in an oven at $40 \pm 2^{\circ} \mathrm{C}$ until a constant mass was reached. A mass change of less than $0.1 \%$ over a period of 24 hours was defined as constant mass. After that, the specimens were put in a climate room at $20 \pm 2{ }^{\circ} \mathrm{C}$ and $60 \%$ relative humidity for 24 hours before the start of the water absorption test. During that period, the lateral faces and the bottom (test) face of the specimens were partly covered with aluminum butyl tape (schematically illustrated in Figure 2). In this way, a confined region of $10 \mathrm{~mm} \times 40 \mathrm{~mm}$ around the crack (or in the middle of the bottom surface in case of the uncracked specimens) was exposed to water during the absorption test.

Before starting the water absorption test, the initial mass of all specimens was registered by

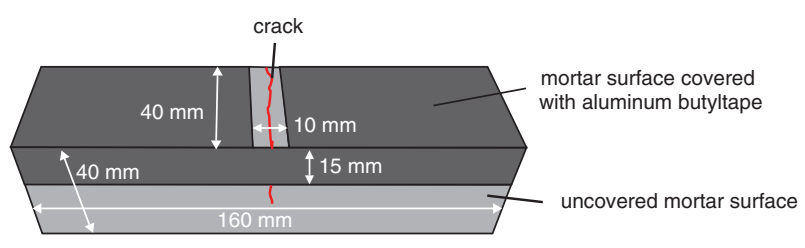

Figure 2. Schematic overview of the partial surface coverage of the mortar prisms with aluminum butyl tape. The top surface in the figure is the test face of the specimen weighing them on a scale with an accuracy of $0.01 \mathrm{~g}$. The specimens were then placed in a plastic container with water on two line supports so that they were immersed up to a depth of $2 \pm 1$ $\mathrm{mm}$. The mass of the specimens was then recorded every half hour during the first eight hours of the test and after this first period the specimens were weighed again after 24, 48, 72 and 96 hours of water exposure.

By subtracting the initial mass of a sample from the recorded mass, the cumulative water uptake was calculated. Subsequently, the cumulative water uptake was divided by the surface area exposed to water during the absorption test. The cumulative water absorption per unit surface area $\left(\mathrm{g} / \mathrm{cm}^{2}\right)$ was then plotted for each specimen separately in function of the square root of immersion time $\left(h^{0.5}\right)$. The gradient of the line from the intercept of the water absorption curve to the cumulative mass of the water uptake per unit area recorded at 24 hours was then defined as the sorption coefficient $\mathrm{S}\left(\mathrm{kg} / \mathrm{m}^{2} / \mathrm{h}^{0.5}\right)$.

\subsection{Examination of the fracture surfaces}

After performance of the capillary absorption test, the specimens with a healed crack were split at the location of the crack in order to evaluate the polyurethane coverage on the crack. This was done in order to have an indication to what extent the PU precursors were able to fill up the crack. Those results could then be linked to the performance of a specimen during the capillary absorption test.

In order to quantitatively determine the surface area of the crack faces that was covered by polyurethane, the hardened PU on the crack surfaces was colored red and a photo of both surfaces was taken. Using the program GIMP, the total area that was colored red on the crack faces and the total cross sectional area of the specimens was determined. In this way, the percentage of the cross section covered by polyurethane was calculated.

\section{RESULTS AND DISCUSSION}

\subsection{Autonomous crack healing}

During the three-point bending test it was seen that the polyurethane precursor was released in the crack almost immediately after breakage of the 
(a) PU_HV (crack width: $73 \mu \mathrm{m}$ )

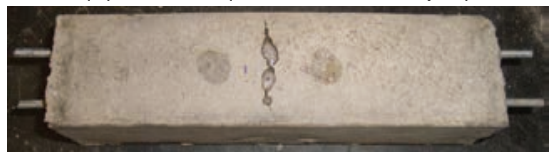

(c) PU_SLV (crack width: $70 \mu \mathrm{m})$ (b) PU_HV (crack width: $252 \mu \mathrm{m})$

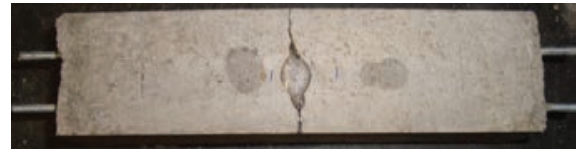

(d) PU SLV (crack width: $232 \mu \mathrm{m})$
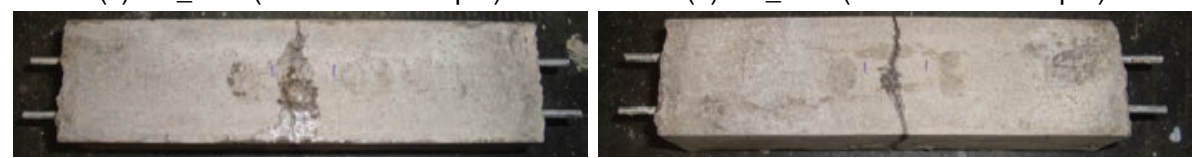

FIGURE 3. Crack healing of (a) a specimen with a relatively small crack width $(<100 \mu \mathrm{m})$ healed by PU_HV, (b) a specimen with a relatively large crack width $(>200 \mu \mathrm{m})$ healed by PU_HV, (c) a specimen with a relatively small crack width $(<100 \mu \mathrm{m})$ healed by PU_SLV and (d) a specimen with a relatively large crack width $(>200 \mu \mathrm{m})$ healed by PU_SLV

capsules. The precursor then reacted with moisture and solidified inside the crack. A few examples of the crack healing are given in Figure 3. In case the crack is healed with the high viscosity polyurethane (PU_HV) the healing of both relatively small cracks (crack width $<100 \mu \mathrm{m}$ ) and relatively large cracks (crack width $>200 \mu \mathrm{m}$ ) is quite similar (Figure 3a and $b$ ). A foaming reaction occurred during hardening of the precursor. Due to this foaming reaction and the high viscosity of the PU precursor, the crack was not always completely healed along the whole crack length. Mostly the cracks were found to be healed quite well in the middle part of the specimen, but sometimes remained unhealed near the edges of the crack (see Figure $3 a$ and $b$ ).

Figure $3 \mathrm{c}$ shows an example of crack healing with PU_SLV for a limited crack width $(<100 \mu \mathrm{m})$. It can be seen that a part of the mortar surface next to the crack was covered with polyurethane. This leakage of polyurethane out of the crack was already noticed during the three-point bending test. It can be attributed to the fact that the PU_SLV precursor flows into the crack quite easily due to its very low viscosity and the crack volume is relatively small. Consequently, a part of the PU flowed out of the crack.

In case a larger crack $(>200 \mu \mathrm{m})$ was healed with PU_SLV (Figure 3d), much less leakage of polyurethane at the bottom of the sample was noticed, because the crack volume was larger. It should be mentioned that even in the case of a crack with a width of $300 \mu \mathrm{m}$, the crack volume remained lower than the total amount of PU precursor in the two capsules. This was done, because from previous research it was noticed that not all of the PU precursor flows out of the capsules when a crack is created (39). Usually only the PU precursor in the central part of the capsules, where the crack causes the rupture, flows into the crack. However, even though not all of the PU precursor flows into the crack, a good crack sealing was noticed visually along the whole length of the crack for both relatively small $(<100 \mu \mathrm{m})$ and large $(>200 \mu \mathrm{m})$ crack widths.

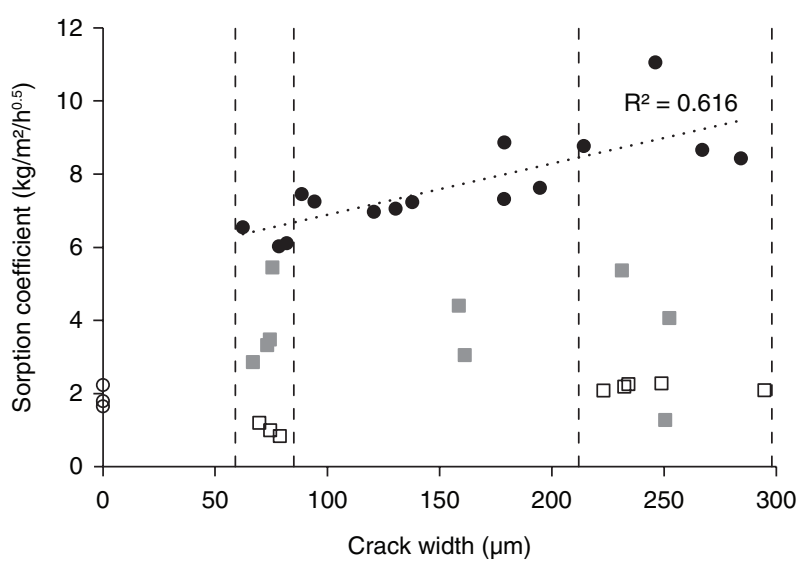

O UNCR • CR $\square$ PU_HV $\square$ PU_SLV

FIGURE 4. Capillary sorption coefficient in function of crack width for uncracked specimens, cracked specimens and specimens healed by PU_HV or PU_SLV. The dotted line represents the linear trend line that was fitted to the data of the cracked specimens. The vertical dashed lines represent the limits for the 'low' and 'high' crack width ranges

\subsection{Capillary water absorption}

\subsection{1. (Un) cracked samples}

Figure 4 shows the capillary sorption coefficients of all tested specimens in function of their crack width. First, the results of the uncracked (crack width equal to zero) and cracked mortar specimens (without crack healing) will be discussed (white and black circles respectively in Figure 4). For uncracked mortar the mean sorption coefficient is $1.89 \mathrm{~kg} / \mathrm{m}^{2} / \mathrm{h}^{0.5}$. The presence of a relatively small crack clearly has a big influence on the capillary water absorption. The sorption coefficient of the mortar prism with the smallest crack that was tested in this research (crack width $=62 \mu \mathrm{m}$ ), was already more than three times higher than the sorption coefficient of the uncracked samples. When comparing samples with relatively small cracks $(62-83 \mu \mathrm{m})$ to samples with crack widths higher than $200 \mu \mathrm{m}$, an increase in the sorption coefficient 
of 29 up to $83 \%$ can be found. A general trend of increasing water absorption with increasing crack width was noticed. This can be clearly seen when a linear trend line is fitted to the data of the cracked specimens (dotted line in Figure 4). In spite of this increasing trend, there is still a lot of scatter in the results. This can mainly be attributed to the fact that the crack width is not the only parameter that influences the capillary water absorption by a crack. Since the cracks were created during a mechanical loading test, the shape, depth and tortuosity of the crack were never the same. These factors also have an influence on the total water uptake through the crack.

Generally it can be concluded that cracks have a major influence on the capillary water absorption of cementitious materials. Clearly, there is a need for repair of the cracks in order to prevent water and other aggressive substances to rapidly penetrate into the matrix.

\subsubsection{Samples with autonomously healed cracks}

The sorption coefficients of the mortar prisms where the cracks were healed by the high viscosity polyurethane (PU_HV) or the low viscosity polyurethane (PU_SLV) are represented in Figure 4 with the grey and white squares, respectively. A first general observation is that the sorption coefficient of the healed specimens is always lower than that of the cracked specimens for all crack widths. In case of crack healing with PU_HV there is a large scatter in the results. This can mainly be attributed to incomplete crack healing for some of the specimens. As mentioned before, this polyurethane showed a foaming reaction along parts of the crack, but near the edges of the specimen the crack sometimes remained unhealed. Another rather remarkable observation is the fact that the crack width does not have a clear influence on the healing efficiency for crack healing with PU_HV.

For crack healing with PU_SLV the healing performance is much more similar for all specimens. For a relatively low crack width, the sorption coefficient of the specimens with healed cracks was even lower than the sorption coefficient of uncracked mortar. The reason for this very high healing efficiency was the fact that a big part of the mortar surface, which was exposed to water during the absorption test, was covered with polyurethane. When the crack width was relatively high $(220-295 \mu \mathrm{m})$ much less polyurethane was noticed at the bottom surface of the specimens (see Figure $3 \mathrm{~d}$ ), but the healing performance was still very good and consistent for all tested specimens. The sorption coefficient of these specimens was comparable to the sorption coefficient of uncracked mortar specimens, which means that there was always almost complete crack healing.

\subsection{Self-healing efficiency}

In order to make a quantitative evaluation of the self-healing performance, the self-healing efficiency (SHE) was determined according to the definition given in Van Belleghem et al. (3). The self-healing efficiency of a mortar specimen [\%] was defined as [1]:

$$
\mathrm{SHE}=\frac{\mathrm{S}_{\mathrm{CR}, \mathrm{M}}-\mathrm{S}_{\mathrm{HEAL}, \mathrm{i}}}{\mathrm{S}_{\mathrm{CR}, \mathrm{M}}-\mathrm{S}_{\mathrm{UNCR}, \mathrm{M}}}
$$

Where $\mathrm{S}_{\mathrm{CR}, \mathrm{M}}$ is the mean sorption coefficient of the cracked specimens $\left[\mathrm{kg} / \mathrm{m}^{2} / \mathrm{h}^{0.5}\right], \mathrm{S}_{\mathrm{HEAL}, \mathrm{i}}$ is the sorption coefficient of an individual healed specimen $\left[\mathrm{kg} / \mathrm{m}^{2} / \mathrm{h}^{0.5}\right]$ and $\mathrm{S}_{\mathrm{UNCR}, \mathrm{M}}$ is the mean sorption coefficient of the uncracked specimens $\left[\mathrm{kg} / \mathrm{m}^{2} / \mathrm{h}^{0.5}\right]$.

The self-healing efficiency was evaluated for two crack width ranges. A 'low crack width range' and a 'high crack width range' were chosen so that at least three specimens of each series (CR, PU_HV and PU_SLV) were in each range. Specimens with crack widths from 62 to $83 \mu \mathrm{m}$ were assigned to the 'low crack width range', specimens with crack widths from 214 to $295 \mu \mathrm{m}$ were assigned to the 'high crack width range'. The two crack width ranges are indicated by the vertical dashed lines in Figure 4.

As mentioned before, the mean value of the sorption coefficient of the uncracked mortar specimens was $1.89 \mathrm{~kg} / \mathrm{m}^{2} / \mathrm{h}^{0.5}$. For the cracked specimens in the 'low crack width range', the mean sorption coefficient was $6.22 \mathrm{~kg} / \mathrm{m}^{2} / \mathrm{h}^{0.5}$. With these two values, the self-healing efficiency of the autonomously healed specimens in the 'low crack width range' could be calculated using Equation 1. For three out of four specimens where crack healing occurred with PU_HV, the self-healing efficiency was between 63 and $78 \%$. However, one specimen performed much worse. A self-healing efficiency of only $18 \%$ was found for this sample. It was also visually observed for this last specimen that only half of the crack at the surface of the specimen was filled with polyurethane. As mentioned previously, crack healing with PU_SLV resulted in a sorption coefficient that was lower than the one obtained for uncracked mortar. Consequently, a self-healing efficiency of more than $100 \%$ was found. For the three specimens in the 'low crack width range', the self-healing efficiency ranged between 116 and $124 \%$.

In the 'high crack width range' the mean sorption coefficient of the cracked specimens amounted to $9.23 \mathrm{~kg} / \mathrm{m}^{2} / \mathrm{h}^{0.5}$. One of the specimens healed with PU_HV showed a very high self-healing efficiency of $108 \%$. The other two specimens in this crack width range performed worse, but the self-healing efficiency still amounted to 53 and $70 \%$. Clearly, a complete crack healing is possible with the high viscosity polyurethane, but it is certainly not always 
the case. Crack healing of cracks in the 'high crack width range' with PU_SLV on the other hand does always show a consistent (almost) complete crack healing. The self-healing efficiency of the five specimens in the 'high crack width range' ranged between 95 and $97 \%$.

\subsection{Cumulative water absorption in function of time}

So far only the sorption coefficients have been used to evaluate the efficiency of the self-healing mechanism. This was a good parameter to compare the different test series, but it does not give complete information about the water absorption process in time. In this section the mean cumulative water absorption curves of the specimens in the 'low crack width range' and the 'high crack width range' are discussed. These curves are presented in Figure 5. From both graphs the major influence of a crack on the ingress of water is very clear. It can be seen that water enters very rapidly into the cracks at the beginning of the absorption test. At the first measurement, after half an hour of exposure to water, the mean total water absorption of specimens with a low crack width is already more than seven times higher than for uncracked specimens. For specimens with a high crack width this is even more than nine times higher. After 24 hours the water absorption rate in the cracked specimens starts to decrease as the specimens get faster to the saturated state. At the end of the test (at 96 hours of exposure) the total water absorption for specimens with a low crack width is nearly three times higher than the water absorption in uncracked specimens and four times higher in case of specimens with a high crack width.

Crack healing of specimens in the 'low crack width range' with PU_HV resulted in a capillary water absorption that was in between the water absorption of uncracked and cracked specimens (Figure 5a). The mean self-healing efficiency of this polyurethane for low crack widths is for all time steps between 51 and 58\%. The self-healing efficiency was calculated at each time step according to Equation 1 by taking the values of the water absorption $\left(\mathrm{g} / \mathrm{cm}^{2}\right)$ instead of the capillary sorption coefficient. The large standard error of this absorption curve is attributed to the fact that a bad healing performance was found for one of the tested specimens, as discussed in the previous section.

Crack healing of small cracks with PU_SLV resulted in complete crack healing. The cumulative absorption curve is located completely under the curve of uncracked samples (self-healing efficiency ranging from 108 to $120 \%$ ). During the first eight hours of the absorption test the water absorption rate of the healed specimens is lower than for the uncracked specimens, while in the period from 24 to 96 hours the sorption rate of healed and uncracked specimens is almost equal. As mentioned before, this can mainly be attributed to the fact that some polyurethane hardened on the mortar surface (see Figure $3 \mathrm{c}$ ). The partial coverage of the test surface caused a very low sorption rate of the healed specimens in the beginning of the test. (a) Low crack width range $62-83 \mu \mathrm{m}$

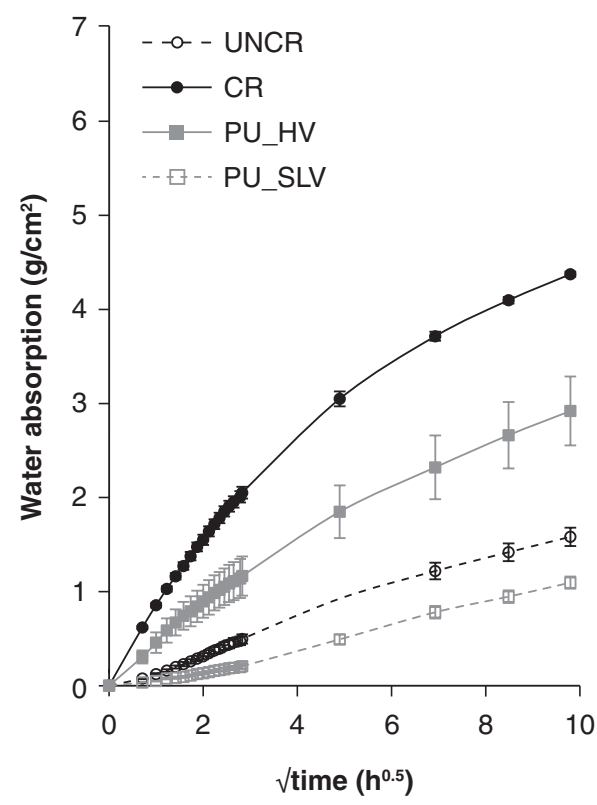

(b) High crack width range $214-295 \mu \mathrm{m}$

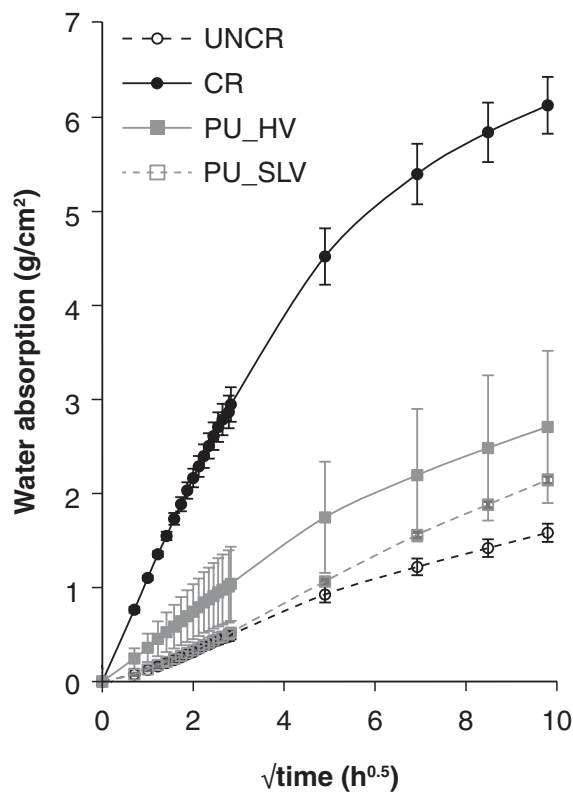

FIGURE 5. Cumulative water absorption curves in function of the square root of time for (a) specimens in the 'low crack width range' and (b) specimens in the 'high crack width range'. Error bars represent the standard error on the mean values 
For cracks in the 'high crack width range', crack healing with PU_HV resulted in a better healing performance than for low crack widths. The mean self-healing efficiency at all time steps was between 75 and $78 \%$. Nevertheless, Figure 5b shows a very large standard error on the test results of the specimens healed with PU_HV. The large variability in healing performance was already noticed before by the large scatter on the sorption coefficients at high crack width (Figure 4).

PU_SLV was able to reduce the water absorption through cracks with a relatively high crack width up to the level of uncracked mortar during the first eight hours of the absorption test (self-healing efficiency of $99-100 \%$ ). After the first eight hours however, the water absorption rate of the healed specimens started to be higher than for the uncracked specimens. The specimens healed with PU_SLV do not behave as good as uncracked specimens anymore, but the self-healing efficiency still amounts to $88 \%$ after 96 hours of exposure to water. A possible cause for this increase in sorption rate could be that only the bottom part of the crack (below the level of the capsules) was healed. Water could then have penetrated into the mortar matrix next to the crack and reached the upper part that was not well healed. However, the evaluation of the crack surfaces in the next section provides proof that there was good filling of the crack in both the part below and above the capsules. Therefore, the increase in water absorption was not caused by incomplete crack filling. Another possible reason is that crack creation might have induced some damage to the bond between the mortar and the reinforcement bars. After eight hours, the water front in the matrix next to the crack most probably reached the position of the reinforcement bars. Some damage at the interface between the rebars and the mortar in the crack area could have caused an increase in the water absorption rate. However, this last hypothesis remains uncertain and could be validated in future research through visualization of the water uptake with X-ray or neutron radiography experiments.

\subsection{Evaluation of the crack surfaces}

Figure 6 shows a few examples of the crack surfaces of healed specimens in the 'low' and 'high' crack width ranges after splitting. As mentioned before, the hardened polyurethane on the crack faces was colored red in order to be able to distinguish it better from the mortar matrix. For the representative specimens in Figure 6 the original crack width is noted along with the total percentage of the cross section that was covered with polyurethane. An overview of the coverage percentage of the cross section of all specimens is given in Table 2. The total coverage percentage (CP) was taken as the sum of the coverage of both halves. This is justified since the fracture always occurred at the contact surface between the polyurethane and the mortar, so part of the polyurethane stuck to one half and another part to the other half after splitting the specimen.

All coverage percentages mentioned in Table 2 are relative to the total cross section of the prism. However, for both small and large crack width ranges the cracks did not run through the whole cross section. This is most clearly visible for the cracks in the 'low crack width range' (Figure 6a and c): no polyurethane was found at the top half of the

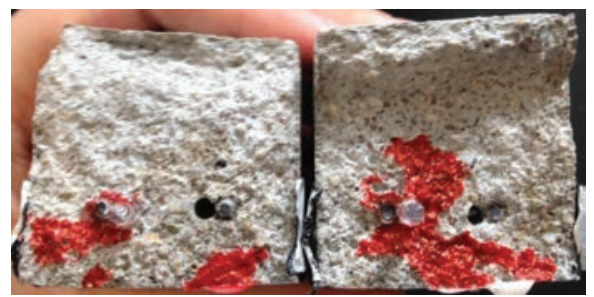

(a) $74 \mu \mathrm{m} / 29 \%$

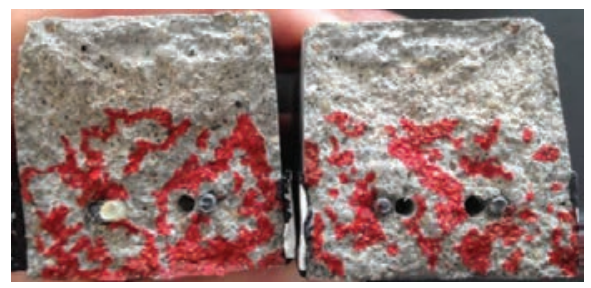

(c) $79 \mu \mathrm{m} / 52 \%$

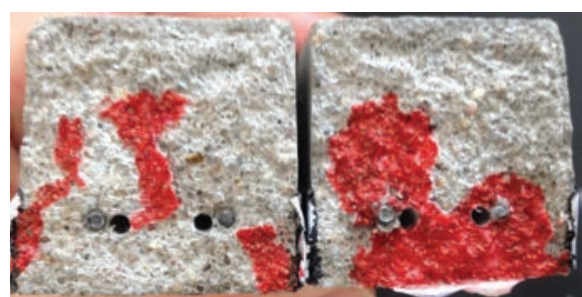

(b) $251 \mu \mathrm{m} / 56 \%$

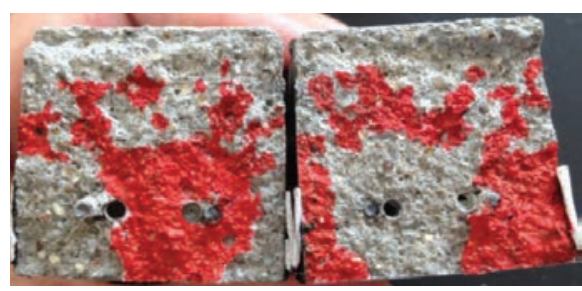

(d) $249 \mu \mathrm{m} / 83 \%$

FIGURE 6. Examples of the crack faces of the healed specimens after splitting (hardened polyurethane colored red). One representative sample is shown of (a) a crack in the 'low crack width range' healed with PU_HV, (b) a crack in the 'high crack width range' healed with PU_HV, (c) a crack in the 'low crack width range' healed with PU_SLV and (d) a crack in the 'high crack width range' healed with PU_SLV. The original crack width of the specimen and the coverage percentage of the cross section are denoted below each specimen 
TABLE 2. Coverage percentage of the cross section with PU of all healed specimens in the 'low' and 'high' crack width range

\begin{tabular}{lcc}
\hline Designation & $\begin{array}{c}\text { Crack width } \\
(\boldsymbol{\mu} \mathbf{m})\end{array}$ & $\begin{array}{c}\text { Coverage percentage of cross } \\
\text { section with PU (\%) }\end{array}$ \\
\hline PU_HV 'low & 67 & 45 \\
crack width & 73 & 29 \\
range' & 74 & 29 \\
& 76 & 29 \\
PU_SLV 'low & 70 & 46 \\
crack width & 75 & 48 \\
range' & 79 & 52 \\
& 231 & 36 \\
PU_HV 'high & 251 & 56 \\
crack width & 252 & 57 \\
range' & 223 & 76 \\
PU_SLV 'high & 232 & 73 \\
crack width & 234 & 80 \\
range' & 249 & 83 \\
& 295 & 83 \\
\hline
\end{tabular}

cross section. This is simply because the crack did not reach the top of the specimen. Consequently, it was not possible to find a coverage percentage of $100 \%$, but it is possible however that there was complete crack filling.

In case of crack healing in the 'low crack width range' with PU_HV, three out of four specimens had a CP of only $29 \%$. However for two out of these three specimens a sorption coefficient of around 3.5 $\mathrm{kg} / \mathrm{m}^{2} / \mathrm{h}^{0.5}$ was found, while a much higher sorption coefficient of nearly $5.5 \mathrm{~kg} / \mathrm{m}^{2} / \mathrm{h}^{0.5}$ was found for the third one. The main reason for the bad healing behavior of this last specimen is that one side of the crack was not healed. No polyurethane coverage was found on one side of the cross section. This shows that not only the $\mathrm{CP}$ of the cross section is important, but also a complete filling of the crack over the whole width cross section is necessary to obtain a good healing performance.

When the crack healing occurred with the PU SLV in the 'low crack width range' very similar values of the CP were obtained: between 46 and $52 \%$. These values are also higher than the values found for PU_HV. When comparing Figures $6 \mathrm{a}$ and $6 \mathrm{c}$ it is also visible that healing with PU_SLV results in a more complete filling of the crack over the whole width of the cross section. This is mainly the result of the very low viscosity of the polyurethane which allows it to flow more easily in the crack.

Healing of cracks with PU_HV in the 'high crack width range' resulted in a large scatter of the sorption coefficient. For the specimen with the smallest crack width in this range $(231 \mu \mathrm{m})$ the largest sorption coefficient was found. This can be attributed to the small $\mathrm{CP}$ of $36 \%$ that was found on the cross section (Table 2). The other two specimens had a similar CP (56-57\%), but the sorption coefficient of one of them was three times smaller than the sorption coefficient of the other. Evaluation of the cross section again showed that for the specimen that performed worse, no complete healing over the whole width of the cross section was found. Most probably that was the main reason why the sorption coefficient of that specimen was much higher.

Figure $6 \mathrm{~d}$ shows that when crack healing occurred with PU_SLV for cracks in the 'high crack width range' there was a very complete filling of the crack over the whole width of the cross section. Coverage percentages between 73 and $83 \%$ were found for all five specimens in this series. These high values for the CP agree well with the low sorption coefficients that were found for these specimens. The increase of water absorption rate after eight hours of water exposure of these specimens mentioned in section 4.4 is thus certainly not caused by an incomplete filling of the upper part of the crack.

\section{CONCLUSIONS}

The presence of cracks in cementitious materials has a detrimental influence on the ingress of aggressive substances. This was already shown in a lot of research and is confirmed in this study by investigating the capillary water absorption of cracked mortar specimens. Relatively small cracks of $62-83 \mu \mathrm{m}$ were already able to cause an increase of $300 \%$ in capillary water absorption. For larger cracks $(>200 \mu \mathrm{m})$ the total water absorption of the mortar specimens could be up to six times higher than for uncracked mortar. Clearly, repair of cracks is necessary to avoid the fast ingress of aggressive substances into the cementitious matrix. In this research, an autonomous healing mechanism was incorporated in the cementitious material by means of capsules with a polyurethane based healing agent. Healing of cracks with different crack widths ranging from 62 to $295 \mu \mathrm{m}$ was investigated.

A commercially available low viscosity polyurethane (PU_SLV) showed the best healing performance. For both relatively small and large crack widths, complete sealing of the crack was found. In the 'low crack width range' $(62-83 \mu \mathrm{m})$ the water absorption of the healed specimens was even lower than for uncracked specimens. Consequently, selfhealing efficiencies higher than $100 \%$ were found. The main reason for these very high values of the healing efficiency was the fact that a part of the healing agent leaked out of the crack and hardened at the mortar surface. Consequently, a big part of the surface area exposed to water during the absorption test was covered with polyurethane. This excess of polyurethane at the surface might have a negative influence from an aesthetical point of view, but 
it does completely prevent water ingress through the crack. PU_SLV was also very efficient for the autonomous healing of larger cracks (214 - 295 $\mu \mathrm{m})$. Much less leakage of the healing agent at the surface of the specimens was found because of the larger crack volume. Still, the self-healing efficiency amounted to $95-97 \%$. After splitting the specimens, it was found that the polyurethane was indeed able to cover most of the crack region.

Crack healing with the non-commercial high viscosity polyurethane (PU_HV) was much less consistent than healing with PU_SLV. Due to the high viscosity of this polyurethane and the foaming reaction, cracks were sometimes not completely healed over the whole length of the crack. This resulted in a large scatter in the capillary water absorption and the self-healing efficiency. Examination of the crack faces after splitting the specimens also showed that less area of the crack was covered by PU compared to the low viscosity healing agent. Also, for some specimens the polyurethane surface coverage was not over the whole width of the cross section. This confirms the fact that the cracks were sometimes not healed over the whole length.

Although the healing of the cracks varied a lot for different specimens, a healing efficiency of 108\% was found for one specimen with a crack width of $251 \mu \mathrm{m}$. This means that complete crack healing of a relatively large crack is possible with PU_HV. Overall, the capillary ingress of water in self-healing specimens with PU_HV was in between the ingress of water in cracked and uncracked samples.

Autonomous healing by encapsulated polyurethane can be very effective in reducing the capillary ingress of water through cracks in cementitious materials. The polyurethane PU_SLV shows the best performance in reducing capillary water absorption. However, the selection of a good healing agent depends on the application of the element. For concrete elements where there is a risk for thermal cracks, for example due to sun radiation, a highly viscous healing agent (e.g. the PU_HV) may be more suitable since the temperature will affect the viscosity of the healing agent. In general, crack healing by the proposed autonomous healing mechanism is beneficial for the durability of the cementitious materials and can extend the lifetime of structures.

Finally, it should be mentioned that all tests carried out in this work were on laboratory scale. In order to extend the lifetime of real reinforced concrete structures, the practical implementation of the self-healing mechanism is also important. First of all, the autonomous healing mechanism should only be incorporated in concrete elements that are vulnerable to service load-induced cracking, e.g. concrete beams or slabs that are subjected to tensile stresses. Secondly, for these elements it is important to incorporate the healing mechanism at the places where it is most needed. The main purpose of the healing action is to prevent aggressive substances to penetrate the concrete matrix and rapidly reach the steel reinforcement. For that reason, the healing mechanism should be incorporated in the cementitious matrix in the concrete cover of the reinforcing steel. This can be done by placing a network of capsules in certain regions of the concrete elements where crack formation is most feared. An example of the implementation of the autonomous healing mechanism through a network of capsules in a large scale element can be found in (40).

\section{ACKNOWLEDGEMENTS}

The current research was performed in the framework of the ISHECO project (Impact of SelfHealing Engineered Materials on steel COrrosion of reinforced concrete) under the program SHE (Engineered Self-Healing materials). The research was funded by SIM (Strategic Initiative Materials in Flanders) and VLAIO (Flanders Innovation \& Entrepreneurship). The financial support from the foundations for this study is gratefully appreciated. Kim Van Tittelboom is a postdoctoral fellow of the Research Foundation-Flanders (FWO) (project number 12A3314N) and acknowledges its support.

\section{REFERENCES}

1. The Concrete Society; Clarke, J.L. (2009) Historical approaches to the design of concrete buildings and structures (Concrete Society Technical Report TR70). The Concrete Society, Camberley.

2. Cailleux, E.; Pollet, V. (2009) Investigations on the development of self-healing properties in protective coatings for concrete and repair mortars. Proceedings of the second international conference on self-healing materials. 120.

3. Van Belleghem, B.; Van den Heede, P.; Van Tittelboom, K.; De Belie, N. (2017) Quantification of the service life extension and environmental benefit of chloride exposed self-healing concrete. Materials 10 [1], 5. https://doi. org/10.3390/ma10010005

4. Martys, N.S.; Ferraris, C.F. (1997) Capillary transport in mortars and concretes. Cement Concrete Res. 27 [5], $747-$ 760. https://doi.org/10.1016/S0008-8846(97)00052-5

5. Wang, L.C. (2014) Experimental study on water absorption by concrete damaged by uniaxial loading. 4th International Conference on the Durability of Concrete Structures. West Lafayette, USA. https://doi.org/10.5703/1288284315402

6. Van Belleghem, B.; Montoya, R.; Dewanckele, J.; Van den Steen, N.; De Graeve, I.; Deconinck, J.; Cnudde, V.; Van Tittelboom, K.; De Belie, N. (2016) Capillary water absorption in cracked and uncracked mortar - A comparison between experimental study and finite element analysis. Constr. Build. Mater. 110, 154-162. https://doi. org/10.1016/j.conbuildmat.2016.02.027

7. NBN EN 1992-1-1. (2005) Design of concrete structures Part 1-1: General rules and rules for buildings. European committee for Standardization. Brussels, Belgium.

8. Li, V.C.; Lim, Y.M.; Chan, Y.-W. 1998. Feasibility Study of a Passive Smart Self-healing Cementitious Composite. Compos. Part B 29 [6], 819-827. https://doi.org/10.1016/ S1359-8368(98)00034-1

9. Mihashi, H.; Nishiwaki, T. (2012) Development of engineered self-healing and self-repairing concrete - State-ofthe-art report. J. Adv. Concr. Technol. 10 [5], 170-184. doi: https://doi.org/10.3151/jact.10.170. 
10. Van Tittelboom, K.; De Belie, N. 2013. Self-healing cementitious materials - A review. Materials 6 [6], 21822217. https://doi.org/10.3390/ma6062182

11. Joseph, C.; Jefferson, A.D.; Isaacs, B.; Lark, R.J.; Gardner, D.R. (2010) Experimental investigation of adhesive-based self-healing of cementitious materials. Mag. Concrete Res. 62 [11], 831-843. https://doi.org/10.1680/macr.2010.62.11.831

12. Sun, L.; Yu, W.; Ge, Q. (2011) Experimental research on the self-healing performance of micro-cracks in concrete bridge. Adv. Mater. Res. 250-253: 28-32. https://doi. org/10.4028/www.scientific.net/AMR.250-253.28

13. Dry, C.M. (2000) Three designs for the internal release of sealants, adhesives, and waterproofing chemicals into concrete to reduce permeability. Cem. Concr. Res. 30 [12], 19691977. https://doi.org/10.1016/S0008-8846(00)00415-4

14. Yang, Y.; Yang, E-H.; Li, V.C. (2011) Autogenous healing of engineered cementitious composites at early age. Cement Concrete Res. 41 [2], 176-183. https://doi.org/10.1016/j. cemconres.2010.11.002

15. Homma, D.; Mihashi, H.; Nishiwaki, T. (2009) Self-healing capability of fibre reinforced cementitious composites. J. Adv. Concr. Technol. 7 [2], 217-228.

16. Ferrara, L; Krelani, V; Moretti, F. 2016. On the use of crystalline admixtures in cement based construction materials: From porosity reducers to promoters of self healing. Smart Mater. Struct. 25 [8], 084002. https://doi. org/10.1088/0964-1726/25/8/084002

17. Ferrara, L.; Krelani, V.; Moretti, F. (2016) Autogenous healing on the recovery of mechanical performance of High Performance Fibre Reinforced Cementitious Composites (HPFRCCs): Part 2-Correlation between healing of mechanical performance and crack sealing. Cement Concrete Comp. 73, 299-315. https://doi. org/10.1016/j.cemconcomp.2016.08.003

18. Lee, H.X.D.; Wong, H.S.; Buenfeld, N. (2010) Self-sealing cement-based materials using superabsorbent polymers. Proceedings of the International RILEM Conference on Use of Superabsorbent Polymers and Other New Additives in Concrete. Lyngby, Denmark: 171-178.

19. Snoeck, D.; De Belie, N. (2015) Repeated autogenous healing in strain-hardening cementitious composites by using superabsorbent polymers. J. Mater. Civil Eng. 28 [1], https://doi.org/10.1061/(ASCE)MT.1943-5533.0001360

20. Janssen, D. (2011) Water Encapsulation to Initiate SelfHealing in Cementitious Materials. Master's Thesis, Delft University of Technology, Delft, The Netherlands.

21. Qian, S.Z.; Zhou, J.; Schlangen, E. (2010) Influence of curing condition and precracking time on the self-healing behavior of Engineered Cementitious Composites. Cement Concrete Comp. 32 [9], 686-693. https://doi.org/10.1016/j. cemconcomp.2010.07.015

22. Snoeck, D.; Van Tittelboom, K.; Steuperaert, S.; Dubruel, P.; De Belie, N. (2014) Self-healing cementitious materials by the combination of microfibres and superabsorbent polymers. J. Intel. Mater. Syst. Str. 25 [1], 13-24. https:// doi.org/10.1177/1045389X12438623

23. Snoeck, D.; De Belie, N. (2015) From straw in bricks to modern use of microfibers in cementitious composites for improved autogenous healing - A review. Constr. Build. Mater. 95, 774-787. https://doi.org/10.1016/j. conbuildmat.2015.07.018

24. Yang, Y.; Lepech, M.D.; Yang, E.-H.; Li, V.C. (2009) Autogenous healing of engineered cementitious composites under wet-dry cycles. Cem. Concr. Res. 39 [5], 382-390. https://doi.org/10.1016/j.cemconres.2009.01.013

25. Van Tittelboom, K.; De Belie, N.; De Muynck, W.; Verstraete, W. (2010) Use of bacteria to repair cracks in concrete. Cem. Concr. Res. 40 [1], 157-166. https://doi. org/10.1016/j.cemconres.2009.08.025
26. Jonkers, H.; Thijssen, A.; Muyzer, G.; Copuroglu, O.; Schlangen, E. (2010) Application of bacteria as selfhealing agent for the development of sustainable concrete. Ecol. Eng. 36 [2], 230-235. https://doi.org/10.1016/j. ecoleng.2008.12.036

27. Luhar, S.; Gourav, S. (2015) A review paper on self healing concrete. J. Civil Eng. Res. 5 [3], 53-58.

28. Van Tittelboom, K.; De Belie, N. (2013) Self-healing in cementitious materials - A review. Materials 6 [6], 21822217. https://doi.org/10.3390/ma6062182

29. Wang, J.; Ersan, Y.C.; Boon, N.; De Belie, N. (2016) Application of microorganisms in concrete: a promising sustainable strategy to improve concrete durability. Appl. Microbiol. Biot. 100 [7], 2993-3007. https://doi.org/10.1007/ s00253-016-7370-6

30. Souradeep, G.; Dai, P.S.; Wei, K.H. Autonomous healing in concrete by bio-based healing agents - A review. Constr. Build. Mater. 146, 419-428. https://doi.org/10.1016/j. conbuildmat.2017.04.111

31. Vijay, K.; Murmu, M.; Deo, S.V. (2017) Bacteria based self healing concrete - A review. Constr. Build. Mater. 152, 1008-1014. https://doi.org/10.1016/j.conbuildmat. 2017.07.040

32. Van Tittelboom, K., De Belie, N., Van Loo, D., Jacobs, P. (2011) Self-healing efficiency of cementitious materials containing tubular capsules filled with healing agent, Cement Concrete Comp. 33, 497-505. https://doi. org/10.1016/j.cemconcomp.2011.01.004

33. Feiteira, J.; Gruyaert, E.; De Belie, N. (2016) Self-healing of moving cracks in concrete by means of encapsulated polymer precursors. Constr. Build. Mater. 102, 617-678. https://doi.org/10.1016/j.conbuildmat.2015.10.192

34. Kanellopoulos, A.; Qureshi, T.S.; Al-Tabbaa, A. (2015) Glass encapsulated minerals for self-healing in cement based composites. Constr. Build. Mater. 98, 780-791. https://doi.org/10.1016/j.conbuildmat.2015.08.127

35. Van Belleghem, B.; Dewanckele, J.; Cnudde, V.; De Belie, N. (2015) Analysis and visualization of water uptake in cracked and healed mortar by water absorption tests and $\mathrm{X}$-ray radiography. 4th international conference on concrete repair, rehabilitation and retrofitting. Leipzig, Germany, 45-53.

36. Van den Heede, P.; Van Belleghem, B.; Alderete, N.; Van Tittelboom, K.; De Belie, N. (2016) Neutron radiography based visualization and profiling of water uptake in (un)cracked and autonomously healed cementitious materials. Materials 9 [5], 311. https://doi.org/10.3390/ ma9050311

37. Gruyaert, E.; Feiteira, J.; De Belie, N.; Malm, F.; Nahm, M.; Grosse, C.U.; Tziviloglou, E.; Schlangen, E.; Tsangouri, E. (2016) Non-destructive testing techniques to evaluate the healing efficiency of self-healing concrete at lab-scale. Emerging Technologies in Non-Destructive Testing VI, Proceedings, 227-233.

38. NBN EN 13057. (2002) Products and systems for the protection and repair of concrete structures - Test methods - Determination of resistance to capillary absorption. European committee for Standardization. Brussels, Belgium.

39. Feiteira, J. (2017) Encapsulated polymer precursors as healing agents for active cracks. Ph.D. Thesis, Ghent University, Ghent, Belgium.

40. Van Tittelboom, K.; Wang, J.; Araújo, M.; Snoeck, D.; Gruyaert, E.; Debbaut, B.; Derluyn, H.; Cnudde, V.; Tsangouri, E.; Van Hemelrijck, D.; De Belie, N. (2016) Comparison of different approaches for selfhealing concrete in a large-scale lab test. Constr. Build. Mater. 107, 125-137. https://doi.org/10.1016/j. conbuildmat.2015.12.186 